\title{
MARITAL SATISFACTION AND EXTRAMARITAL BEHA- VIORAL INTENTIONS IN MEDICAL PROFESSIONALS
}

\author{
Ayesha Mansoor, ${ }^{1}$ Shazia Khalid ${ }^{2}$
}

\begin{abstract}
Objectives: The present research was conducted to investigate the relationship between marital satisfaction and extramarital behavioral intentions in medical professionals.
\end{abstract}

Study Design: Cross - sectional research design was used to conduct the present study.

Material And Methods: Relationship Assessment Scale constructed by Hendrick in 1988 was used to assess marital satisfaction of the study sample. ${ }^{1}$ Extramarital behavioral intentions were assessed by using extramarital behavioral intentions scale by Buunk in $1981{ }^{2}$ Cross sectional research design was used in the research. Correlation, hierarchal regression, one way ANOVA and independent sample t-test was applied for analysis using SPSS version 16.0.

Results: Overall, the results proved that there is a negative relation among marital satisfaction and extramarital behavioral intentions. Male participants are likely to indulge in extramarital behavioral intentions than female participants. Whereas participants who had love marriage and had lesser number of children were more martially satisfied than those who had arranged marriage. Demographic variables collectively

Mansoor A. ${ }^{1}$

Institute of Applied Psychology, University of the Punjab

Khalid S. ${ }^{2}$

Assistant Professor

Institute of Applied Psychology, University of the Punjab accounted for $11 \%$ of the variance and extramarital behavioral intentions overall accounted for $5 \%$ of variance predicting marital satisfaction.

Conclusion: Marital satisfaction and extramarital behavioral intentions in medical professionals are negatively correlated.

Keywords: Marital Satisfaction, Extramarital behavioral intentions, Medical Professionals.

\section{Introduction}

Among all the interpersonal relationships, marriage is the most important one. Mostly people get married at least once in their life. ${ }^{3}$ Marriage is expected to be a source of satisfaction. ${ }^{3-5}$ Marital satisfaction is a psychological phenomenon that imitates the supposed profits and costs of marriage to a specific individual that is known to be as spouse. ${ }^{6}$ Medicine is the discipline and art of curing and medical professionals are the individuals who provide the understanding to the patient's problems and heal them with the help of medicine. Among various desires and attitudes of human beings, extramarital affairs have become very common in modern era which includes dating through internet, at workplace and other means of communication. One can no longer belief in his or her spouse or feel harmless within the relationship. ${ }^{7-9}$ Extramarital behavioral intentions can be defined according to model presented by Fishbein and Ajzen in 1975 which states that, a behavioral intention is an idiosyncratic probability that someone will exhibit a certain behavior if the opportunity presents itself. ${ }^{10}$ It highly associates with future 
behavior. ${ }^{11}$ This concept is also elaborated by intention behavior relationship model based on theory of planned behavior which explains that perceived norms, self efficacy and attitude of individual forms intentions leading to behavior or act.

The reason behind opting medical professionals as study sample was because these individuals tend to have empathetic relation towards patients. Another reason was the ease of access to study subjects as the survey was conducted in the hospital setting. As observed, doctors have access to patients and subordinates like paramedics, nurses, junior staff and internees. They not only cure the ill with motivation but also tend to give them hope for betterment. Also they encounter with variety of people on daily basis whom they have to treat with courtesy, fine communication and empathy. Similarly, another focus of interest was to search level of satisfaction of study sample in their marital life along with professional life. Through the results of current research, extramarital behavioral intentions in individuals were assessed and predicted marital satisfaction. The current research has possible implications in the field of marital and counseling psychology.

\section{Literature Review}

There is consistent evidence from the researches done on socializing and wedded couples. She designed a study to compare medical professionals on a number of vocation designs, efficiency, family organization and sex differences. ${ }^{12}$ The results discovered sex differences in operative, vicarious communication and position of men and women doctors comparable to those found in other countries. Fisher conducted a study entitled, "The influence of communally transported standards on the reporting of sexual behavior and approaches by men and women". The study consisted college students as sample for investigation. It was revealed that those men and women who had permissive conditions reported more extra dyadic involvement than those in conservative environment. ${ }^{13}$ Also VanLaningham, Johnson, and Amato found that marital satisfaction follows a more linear declining trajectory, with steep declines in the initial and the newest years of marriage ${ }^{14}$. Similarly, Glass and Wright gave the justifications for extramarital relationships in their research. Married people accomplished unidentified surveys rating the degree to which they would sense defensible of having an extramarital relationship for 17 reasons resulting from the experimental and research writings. Men and women gathered these defenses likewise into four factors: sexual, romantic love, emotional intimacy, and extrinsic. Women accepted fewer sexual defenses and more of affection explanations. The statistics sustained the thought that men isolated sex and love; women seem to rely on that love and sex go collectively and that falling in love defends sexual connection. ${ }^{15}$

\section{Material and Methods}

By using purposive sampling technique, 150 medical professionals, of which male $(\mathrm{n}=75)$ and female $(n=75)$ married doctors of government and private sector hospitals were taken. The hospitals for data collection were chosen according to ease to access the study sample through permission from administrative authorities. Two government sector and two private sector hospitals were chosen to study the research variables. Cross sectional research design was selected for the study. Participants were permanent employees at hospitals in order to assess the study variables because permanent employees were suspected to have more interaction and affiliation with hospital staff, colleagues, regular follow up patients, paramedics and other employees. Participants with second marriage, divorced and widowed were not included in the study. Scores obtains from relationship assessment scale (RAS) by Hendrick, 1988 was an index of martial satisfaction with .8 reliability. Similarly, scores on extramarital behavioral intentions scale (EBIS) by Buunk, 1981 is the index of extramarital behavioral intentions which has .70 as Cronbach alpha reliability and .74 validity. Demographic information was collected through a self - constructed demographic sheet including age, gender, education, type of marriage ,years of marriage, age of wife / husband, number of children, family system, years of professional practice, is Wife/husband working or non-working, profession of wife/husband if working, comfortableness while interaction with opposite gender (ease to informal conversation) in Yes or No terms.

Before collecting the data, permission was sought for the use of tools for measuring both the variables from the respective authors of the scales. Prior to data collection, official permission was taken from the concerned authority on the data collection through a letter by Institute of Applied Psychology. After taking permission from authorities, the tools were administered 
on the sample population. The purpose of the research was explained to every participant. A consent form was given to the participants for the contribution in research. Only those participants were encompassed in the study that showed willingness for the participation in the research. They were assured about the confidentiality of the responses as well the right of withdrawal from the research at any time without any penalty. After that questionnaires were provided to the participants. All the assessment measures were filled by participants. They were instructed to fill all response ite$\mathrm{ms}$ and complete demographic information correctly. The average time of filling all the assessment measure was 10 minutes. The participants were handed over with the assessment measures to be filled alone for ten minutes for the accurate and true responses. After that the results were reported accurately. Discussion was done about the obtained results and consistency and inconsistency of results with previous researches was also mentioned. The information of the participant was only shared with the supervisor. All types of personal biases were kept a side either the hypothesis got proved or rejected. At the end of the data collection, analysis was done by using SPSS. Pearson Product Moment Correlation Analysis was applied to find out the relationship between variables. Hierarchal Regression analysis was also applied for the prediction. Independent sample $\mathrm{T}$ test was also applied to reveal the mean differences in gender with the study variables. One way Anova was run to determine significant differences among grouped demographic variables like education, profession, age groups etc.

\section{Hypotheses}

1. There is likely to be a negative relationship between extramarital behavioral intentions and marital satisfaction among medical professionals.

2. Marital satisfaction is likely to predict extramarital behavioral intentions in study variables.

3. There is likely to be a gender difference for extramarital behavioral intentions and marital satisfaction.

4. Demographic variable such as type of marriage, age of spouse, education, years of marriage, number of children, profession of spouse, family system and working status of spouse are likely predict marital satisfaction.

\section{Results}

The demographics revealed that most of the sample comprised of MBBS degree (66.7\%), with $84 \%$ of total sample having love marriages, $67 \%$ living in nuclear family system and $81 \%$ of sample having working spouses. $100 \%$ of the study sample accounted "yes" for the comfortableness with opposite gender (ease to

Table 1: Pearson Product Moment Correlation between the study variables $(\mathrm{N}=150)$.

\begin{tabular}{|l|l|l|l|l|c|c|c|}
\hline & 1 & 2 & 3 & 4 & 5 & 6 & 7 \\
\hline 1. & - & $.55^{* *}$ & $.80^{* *}$ & $.68^{* *}$ & $-.20^{*}$ & -.08 & .02 \\
\hline 2. & - & - & $.80^{* *}$ & $.63^{* *}$ & -.16 & -.01 & $-23^{* *}$ \\
\hline 3. & - & - & - & $.71^{*}$ & $-.17^{*}$ & -.06 & -.02 \\
\hline 4. & - & - & - & - & -.10 & $.17^{*}$ & -.09 \\
\hline 5. & - & - & - & - & - & .09 & .01 \\
\hline 6. & - & - & - & - & - & - & $-.24^{* *}$ \\
\hline 7. & - & - & - & - & - & - & - \\
\hline
\end{tabular}

Note: $1=$ age, $2=$ age of spouse, $3=$ years of marriage $4=$ no. of children, $5=$ no. of hours with spouse, $6=$ marital satisfaction, $7=\mathrm{EBI}$

Table 2: Summary of Hierarchical Regression.

\begin{tabular}{|l|l|l|}
\hline \multirow{2}{*}{ Predictors } & \multicolumn{2}{|c|}{ Marital Satisfaction } \\
\cline { 2 - 3 } & $\Delta R^{2}$ & $B$ \\
\hline Step 1 & $.11^{*}$ & \\
\hline Age & & .12 \\
\hline Gender & & .14 \\
\hline Type of Marriage & & $.22^{* *}$ \\
\hline Age of Spouse & & .00 \\
\hline Years of Marriage & & .06 \\
\hline Number of Children & & $-.30^{*}$ \\
\hline Family System & & .11 \\
\hline Working Status Spouse & & .01 \\
\hline No. of hours with spouse & & .06 \\
\hline Step 2 & $.05^{* * *}$ & \\
\hline $\begin{array}{l}\text { Extramarital Behavioral } \\
\text { Intentions }\end{array}$ & & $-.24^{* *}$ \\
\hline Total $R^{2}$ & $.16^{* *}$ & \\
\hline
\end{tabular}


informal conversation) demographic. There exists a significant negative relationship among marital satisfaction and extramarital behavioral intentions.

The results in the table of correlation revealed that marital satisfaction is significantly and negatively related to extramarital behavioral intentions. Moreover, age of spouse was found to be significantly and negatively related to extramarital behavioral intentions whereas no other demographics were found significantly related to study variables.

Demographic variables such as age, gender, type of marriage, age of spouse, years of marriage, number of children, family system, working status of spouse, number of hours spent with spouse were entered in the Model 1and extramarital behavioral intentions was entered in the Model 2 and marital satisfaction as dependent variable. All the assumptions of multicollinea- rity, collinearity, outliers, normality, linearity, homoscedasticity, and independence of residuals were satisfactorily fulfilled. ${ }^{16-17}$ (Tabachnick and Fidell, 1996; Cohen, 1988). The model 1 produced $\mathrm{R}$ square of .11 which was statistically significant $(F(9,140)=1.98$, $p<.05)$. It means that predictor variables of age, gender, type of marriage, age of spouse, years of marriage, number of children, family system, working status of spouse, and number of hours spent with spouse collectively accounted for $11 \%$ of the variance in the model. When extramarital behavioral intention was added, the model 2 produced $\mathrm{R}$ square of .05 which was statistically significant $(F(10,139)=2.65, p<.01)$ and extramarital behavioral intention level contributed $5 \%$ of variance in the model. On the other hand, extramarital behavioral intentions $(\beta=-.24, t=-2.80, p<$ $.01)$, type of marriage $(\beta=.22, t=2.61, p<.01)$ and

Table 3: Independent samples t-test comparing mean differences in male and female medical professionals $(\mathrm{N}=150)$.

\begin{tabular}{|l|c|c|c|c|c|c|}
\hline \multirow{2}{*}{\multicolumn{1}{|c|}{ Variables }} & \multicolumn{2}{|c|}{ Males $(\mathrm{n}=75)$} & \multicolumn{2}{c|}{ Females $(\mathrm{n}=75)$} & \multirow{2}{*}{$\mathrm{t}(148)$} & $\mathrm{p}$ \\
\cline { 2 - 7 } & $\mathrm{M}$ & $\mathrm{SD}$ & $\mathrm{M}$ & $\mathrm{SD}$ & & .19 \\
\hline Marital Satisfaction & 30.29 & 3.91 & 31.12 & 3.88 & -1.29 & .00 \\
\hline Extramarital Behavioral Intentions & 6.54 & 2.63 & 5.09 & .41 & 4.73 & .00 \\
\hline
\end{tabular}

Note: $\mathrm{M}=$ Mean; $\mathrm{SD}=$ Standard Deviation; $* \mathrm{p}<.05$

Table 4: Table showing one way ANOVA comparing study variables in research sample for different educational levels $(\mathrm{N}=150)$.

\begin{tabular}{|l|c|c|c|c|c|c|c|c|c|c|}
\hline \multirow{2}{*}{ Variables } & \multicolumn{2}{|c|}{$\begin{array}{c}\text { MBBS/BDS } \\
(\mathrm{n}=102)\end{array}$} & \multicolumn{2}{|c|}{$\begin{array}{c}\text { MBBS/FCPS } \\
(\mathrm{n}=41)\end{array}$} & $\begin{array}{c}\text { MBBS/FCPS/MCPS } \\
(\mathrm{n}=3)\end{array}$ & \multicolumn{2}{c|}{ Postgraduate (n=4) } & \multicolumn{2}{|c|}{} \\
\cline { 2 - 13 } & $M$ & $S D$ & $M$ & $S D$ & $M$ & $S D$ & $M$ & $S D$ & $F(3,146)$ & $p$ \\
\hline Marital Satisfaction & 30.81 & 3.74 & 30.34 & 4.32 & 34.33 & 1.15 & 29.00 & 4.24 & 1.26 & .28 \\
\hline $\begin{array}{l}\text { Extramarital } \\
\text { Behavioral Intentions }\end{array}$ & 5.79 & 2.04 & 6.02 & 2.09 & 5.00 & .00 & 5.00 & .00 & .53 & .66 \\
\hline
\end{tabular}

Note: $\mathrm{M}=$ Mean; $\mathrm{SD}=$ Standard Deviation; $* \mathrm{p}<.05$

Table 5: Table showing one way ANOVA comparing study variables in research sample for different profession of spouse $(\mathrm{N}=150)$.

\begin{tabular}{|l|c|c|c|c|c|c|c|c|}
\hline \multirow{2}{*}{ Variables } & \multicolumn{2}{|c|}{ Teaching $(\mathrm{n}=10)$} & \multicolumn{2}{c|}{ Banking $(\mathrm{n}=3)$} & \multicolumn{2}{c|}{ Others $(\mathrm{n}=137)$} & \multicolumn{2}{l|}{} \\
\cline { 2 - 10 } & $\mathrm{M}$ & $\mathrm{SD}$ & $\mathrm{M}$ & $\mathrm{SD}$ & $\mathrm{M}$ & $\mathrm{SD}$ & $\mathrm{F}(3,146)$ & $\mathrm{P}$ \\
\hline Marital Satisfaction & 29.80 & 4.34 & 27.66 & 4.93 & 30.86 & 3.86 & 1.01 & .39 \\
\hline Extramarital Behavioral Intentions & 6.50 & 3.17 & 5.33 & .57 & 5.78 & 1.93 & .50 & .68 \\
\hline
\end{tabular}

Note: $\mathrm{M}=$ Mean; $\mathrm{SD}=$ Standard Deviation; $* \mathrm{p}<.05$ 

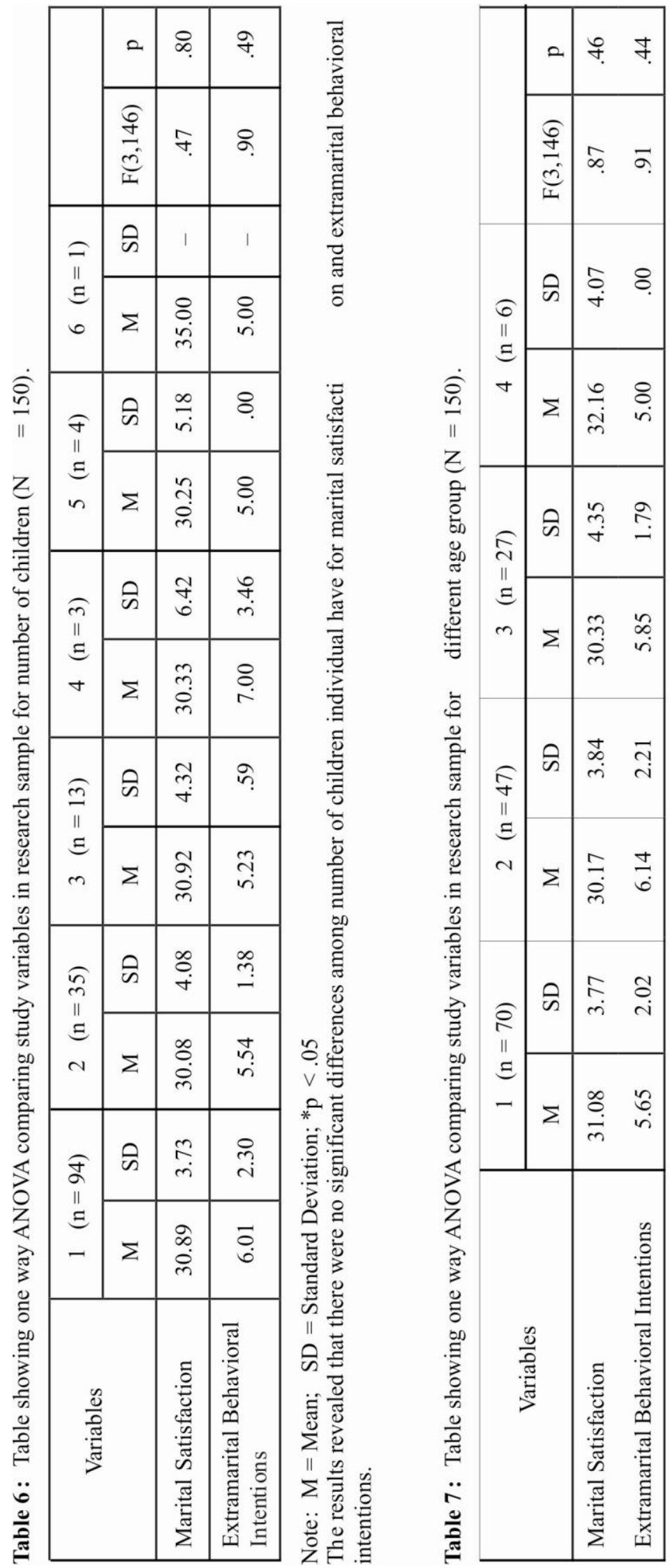

number of children $(\beta=-.30, t=-2.40, p<$ $01)$ significantly predicted marital satisfaction.

The results of independent samples t-test for gender revealed that there are no significant mean differences in the marital satisfaction for male and female medical professionals. Moreover, gender differences were found significant in extramarital behavioral intentions which revealed that male doctors $[(\mathrm{M}=6.54, \mathrm{SD}=2.63)]$ are more likely to indulge in extramarital behavioral intentions than female doctors $[(\mathrm{M}=5.09, \mathrm{SD}=.41)]$.

The results revealed that there were no significant differences among educational level for marital satisfaction and extramarital behavioral intentions for the current study sample.

The results revealed that there were no significant differences among professions of spouse for marital satisfaction and extramarital behavioral intentions.

One way ANOVA was used to explore the differences in the study variables for number of children. The results are displayed in the tabulated form.

The results revealed that there were no significant differences among age groups for marital satisfaction and extramarital behavioral intentions.

\section{Discussion}

Through the current research, three fold benefits were observed. Firstly, it showed how marital satisfaction and extramarital behavioral intentions are related and predicted each other. Secondly, it determined gender differences for the study variables. Thirdly, it depicted how much variance was explained by demographic variables as predictors of marital satisfaction. It was clearly explained in the results that extramarital behavioral intentions is significantly and negatively related to marital satisfaction. It means that individuals who are satisfied with their marriages have less extramarital behavioral intentions and those who are dissatisfied tend to have high extramarital 
intentions. The results had similar findings to a research that extramarital behaviors are related to the marital satisfaction. ${ }^{18-20}$ The results correspond to research which reveals the parallel results that extramarital behaviors are negatively related to marital satisfaction. ${ }^{8}$ The results of the present research reveal that extramarital behavioral intentions predict low marital satisfaction. The results of study of Allen et.al in 2005 suggested that extra didactic relations predict less marital satisfaction and marital conflicts including spousal conflicts, marital discontentment and loss of interest in marriage. ${ }^{21}$ Outcomes of the current study depicted that men tend to be involved in extramarital behavioral intentions more than women. The results correspond to study in which it is evident by Fisbein and Ajzen's work in 1975 that tendency to be involved in extra marital relations was more among men than women. ${ }^{2-}$ ${ }^{25}$ Hoelter, et al., 2004 suggested that children associate with lower marital satisfaction. ${ }^{26}$ This means that lower the number of children, more will be the marital satisfaction. It might be due to the fact that lesser would be the number of children, lesser will be the amount of responsibilities, more will be the amount of quality time spent with children, and more attention would be paid to the wife or husband. The results also showed that people with love marriages were more martially satisfied with those who had arrange marriages. Similarly, Xu and Whyte in 1990 found out that woman who choose their own spouse have higher marital satisfaction. $^{27-28}$

\section{Conclusion}

The current research has assessed extramarital behavioral intentions in medical professionals and have significantly predicted marital satisfaction. The findings are can account for a helpful source as a literature for couple and marital counseling domain.

\section{References}

1. Hendrick, S. S. A generic measure of relationship satisfaction. Journal of Marriage and Family, 1988; 50: 9398.

2. Buunk, B. Social norms and the extramarital sexual behavior intention. Nederlands Tijdschrift voor de Psychologie en haar Grensgebieden, 1981; 36 (1): 65-70.

3. Berschied, E. and Regan, P. The Psychology of Interpersonal Relationships. New Jersy: Prentice Hall, 2005.

4. Hess, J. Marital Satisfaction and Parental Stress. (Gra- duate dissertations, Utah State University), 2008.

5. Spanier, G. B. and Cole, C. L. Toward clarification and investigation of marital adjustment. International Journal of Sociology of the Family, 1976: 121-146.

6. Spring, J. A. and Spring, M. How can I forgive you? The courage to forgive, the freedom not to. Perennial Library / Harper and Row Publishers, 2004.

7. Brown, E. M. Patterns of infidelity and their treatment. Routledge, 2013.

8. Glass, S. P. and Wright, T. L. Justifications for extramarital relationships: The association between attitudes, behaviors, and gender. Journal of sex Research, 1992; 29 (3): 361-387.

9. Miller, D. N. The Relationship between Partner Differences in Jungian Psychological Type and Marital Satisfaction (Doctoral dissertation, Capella University), 2006.

10. Shackelford, T. K. Marital Satisfaction, 2007.

11. Fishbein, M. and Ajzen, I. Belief, attitude, attention and behavior. Reading. MA: Addison-Wesley, 1975.

12. Shye, K. Gender Differences in Israeli Physicians' Career Patterns, Productivity and Family Structure. Personnel Review, 2002; 31 (5): 518-539.

13. Fisher, T. D. The impact of socially conveyed norms on the reporting of sexual behavior and attitudes by men and women. Journal of Experimental Social Psychology, 2009; 45 (3): 567-572.

14. VanLaningham, J., Johnson, D.R., Amato, P. Marital happiness, marital duration, and the U-shaped curve: Evidence from a five - wave panel study. Social Forces 2001; 79: 1313-1341.

15. Fisher, D, T., et.al. Handbook of sexuality - related measures, 2013.

16. Tabachnick, B. and Fidell, L. Using multivariate statistics. New York: Harper and Row, 1996.

17. Cohen J. Statistical Power Analysis for the Behavioral Sciences. $2^{\text {nd }}$ edition. Lawrence Erlbaum Associates, Routledge publisher, 1988.

18. Sho'a' Kazemi M, MomeniJavid M. Studying Couple Psychotherapy Effect on Life Quality Improvement in Damaged Couples from marital Betrays. First Domestic Student Conference on Effective Social Factors on Health, 2010.

19. Drake C, Mccabe M. Extramarital relationship involvement among heterosexual males: An explanation based on the theory of planned behavior, relationship quality, and past behavior. Journal of Applied Social Psychology, 2000; 3 (7): 1421-1439.

20. Javidnia, N., Golzari, M. and Borjali, A. The Relationship between Marital Satisfaction and Extramarital Behavior among Married Women. International Journal of Psychology and Behavioral Research, 2014; 3 (4): 252-257.

21. Allen, E. S., Atkins, D. C., Baucom, D. H., Snyder, D. K., Gordon, K. C. and Glass, S. P. Intrapersonal, interpersonal, and contextual factors in engaging in and res- 
ponding to extramarital involvement. Clinical Psychology: Science and Practice, 2005; 12 (2): 101-130.

22. Kinsey, A. C., Pomeroy, W. B. and Martin, C. E. Sexual behavior in the human male. Philadelphia: W. B. Saunders, 1948.

23. Kinsey, A.C., Pomeroy, W.B., Martin, C.E. and Gebhard, P.H. Sexual behavior in the human female. Philadelphia: W. B. Saunders, 1953.

24. Wiederman, M. W. Extramarital sex: Prevalence and correlates in a national survey. Journal of Sex Research, 1997; 34: 167-174.

25. Hoelter, L.F., Axinn, W.G., Ghimire, D.J. Social change, premarital nonfamily experiences, and marital dy- namics. Journal of Marriage and the Family 2004; 66: 1131-1151.

26. Amato, P. R., Johnson, D. R., Booth, A. and Rogers, S. J. Continuity and change in marital quality between 1980 and 2000. Journal of marriage and family, 2003; 65 (1): 1-22.

27. Xu, X., Whyte, M.K. Love matches and arranged matches: A Chinese replication. Journal of Marriage and the Family, 1990; 52: 709-722.

28. Pimentel, E.F. Just how do I love thee? Marital relations in urban China. Journal of Marriage and the Family, 2000; 62: 32-47. 